\title{
An Approach for Accurate Designing of Transformers Supplying DC Load Currents
}

\author{
M. Sedighizadeh and M. Khatibi
}

\begin{abstract}
Transformers which supply DC load currentsknown as rectifier transformers-face with harmonic problems as the rectifier circuits connected to their secondary windings are based on semiconductor devices and thus, generate harmonic currents. Accurate designing of such transformers highly depends on these harmonic currents. The typical method employed to design these transformers is often time consuming and there is a high risk of various mistakes since it is hardly possible to model the transformer and the rectifier together during the design process. In this paper, an approach is developed for accurate designing of transformers which supply DC load currents. In the proposed approach, a database including 11 types of rectifier circuits, employed a lot for industrial purposes, as well as their harmonic analysis is created by means of computer simulations. Next, the transformer and the selected rectifier are simulated together and the harmonic spectrums existing in individual windings of the transformer are extracted. Finally, transformer parameters are designed based on the extracted harmonic spectrums and their resulting effects. The results of applying the proposed approach to an example of IEEE Standard No.C57.18.10.1998 for semiconductor power rectifier transformers evidently verifies the usefulness of the presented approach.
\end{abstract}

Index Terms-Dc load currents, design, harmonic spectrums, rectifier transformer.

\section{INTRODUCTION}

Due to the need of various industries to DC current and voltage, the use of semiconductor power rectifiers has increased a lot. These rectifiers supply DC load currents but create harmonic components in the current drawn from the source [1]. These harmonic currents affect other equipment employed in a rectifier system. As a result, the transformers utilized in such systems - known as Power Rectifier Transformers - supply non-sinusoidal load currents and are subject to higher harmonic load losses than standard power transformers due to the harmonic currents [2,3]. If the increased losses are not appropriately taken into account in designing process, the transformer will face with severe problems [1]. The key features to be taken into account in designing a rectifier transformer include the RMS value of individual windings currents considering the harmonics, different losses generated by harmonic currents, de-rated power of the transformer from sinusoidal condition so that it

Manuscript received March 7, 2010. This work was supported in part by Imam Khomeini International University under Grant 127690.

M. Sedighizadeh is with Faculty of Engineering and Technology, Imam Khomeini International University, Ghazvin, Iran. (m_sedighi@sbu.ac.ir)

M. Khatibi is with Islamic Azad University - Abhar branch, Abhar, Iran. (Khatibi_masoud@yahoo.com). can operate without over heating, and maximum temperature rise of the oil and windings [4,5]. A design engineer may utilize the above data and make some changes in different parts of the transformer such as type of the tap changers, if any, cooling system, the area of the windings, and the position of bushings. In order to well consider the role of harmonics in designing rectifier transformers, the harmonic spectrums existing in individual windings of the transformer is needed. In order to attain such spectrums, it is better to have in access the rectifier circuit and perform appropriate tests to obtain the harmonic spectrums and the magnitude of existing harmonic components $[1,3,4]$. However, most of rectifier and transformer manufacturers are not easily in touch with each other so it is hardly possible for transformer manufacturers to model the transformer and the rectifier together during the design process and perform the required tests to get the harmonic spectrums. The problem is enlarged when we consider that there are various types of rectifier circuits each having different harmonic spectrums depending on its pulses. Hence, design engineers do the appropriate calculations based on sinusoidal normal operation of the transformer and finally add some correctional factors according to the excising standards, to consider the harmonic conditions. This is practically time consuming and there is a high risk of various inaccuracies. In this paper, an approach is suggested for accurate designing of transformers that supply DC load currents. The proposed approach is based on simultaneous modeling of rectifier circuit and the transformer by means of computer simulations. The organization of this paper is as follows: In Section II, using computer simulations, the harmonic currents spectrums existing in different windings of such transformers are extracted for 11 types of industrially-utilized rectifiers. Next, the effects of harmonic currents on the transformer are reviewed in Section III. The suggested approach is explained in Section IV and a case study is studied in Section V employing the developed approach. Finally, conclusion is presented in Section VI.

\section{SIMULATIONS AND HARMONIC SPECTRUMS}

In order to overcome the aforementioned limitations, 11 types of various rectifiers are selected. The selected rectifier circuits include those which are typically utilized for industrial purposes according to their capabilities and costs $[6,7]$. Next, they are simulated on the computer and the required current waveforms of primary, secondary, and if any, tertiary windings are extracted. The characteristics of the employed rectifier circuits as well as the transformer connected to them are summarized in TABLE I and their block diagrams simulated in MATLAB/SIMULINK are shown in Fig. (1). Fig. (2) shows an example of extracted 
waveforms.

TABLE I CHARACTERISTICS OF SIMULATED RECTIFIERS WITH THE TRANSFORMER CONNECTED TO THEM

\begin{tabular}{|c|c|c|c|c|}
\hline $\begin{array}{c}\text { Rectifier } \\
\text { code }\end{array}$ & $\begin{array}{c}\text { Number } \\
\text { of Pulses }\end{array}$ & Characteristics of the Rectifier & $\begin{array}{c}\text { Transformer } \\
\text { Type }\end{array}$ & $\begin{array}{c}\text { Connection of } \\
\text { Windings }\end{array}$ \\
\hline 1 & 3 & Single way - Not controlled & Two windings & (D/y) or (Y/y) \\
\hline 2 & 3 & Single way - Tyristor controlled & Two windings & $(\mathrm{D} / \mathrm{y})$ or (Y/y) \\
\hline 3 & 6 & Six phase - Not controlled - Without interphase & Two windings & Secondary: Star \\
\hline 4 & 6 & Six phase - Tyristor controlled - Without interphase & Two windings & Secondary: Star \\
\hline 5 & 6 & Bridge model - Not controlled & Two windings & $(\mathrm{D} / \mathrm{y})$ or (Y/y) \\
\hline 6 & 6 & Bridge model - Tyristor controlled & Two windings & $(\mathrm{D} / \mathrm{y})$ or $(\mathrm{Y} / \mathrm{y})$ \\
\hline 7 & 6 & Bridge model - Half controlled & Two windings & $(\mathrm{D} / \mathrm{y})$ or $(\mathrm{Y} / \mathrm{y})$ \\
\hline 8 & 6 & Double way - Not controlled - With interphase & Three windings & $(\mathrm{D} / \mathrm{yy})$ or (Y/yy) \\
\hline 9 & 6 & Double way - Tyristor controlled -With interphase & Three windings & $(\mathrm{D} / \mathrm{yy})$ or $(\mathrm{Y} / \mathrm{yy})$ \\
\hline 10 & 12 & Series connection of two 6-pulse rectifiers & Three windings & Any connection \\
\hline 11 & 12 & Parallel connection of two 6-pulse rectifiers & Three windings & Any connection \\
\hline
\end{tabular}

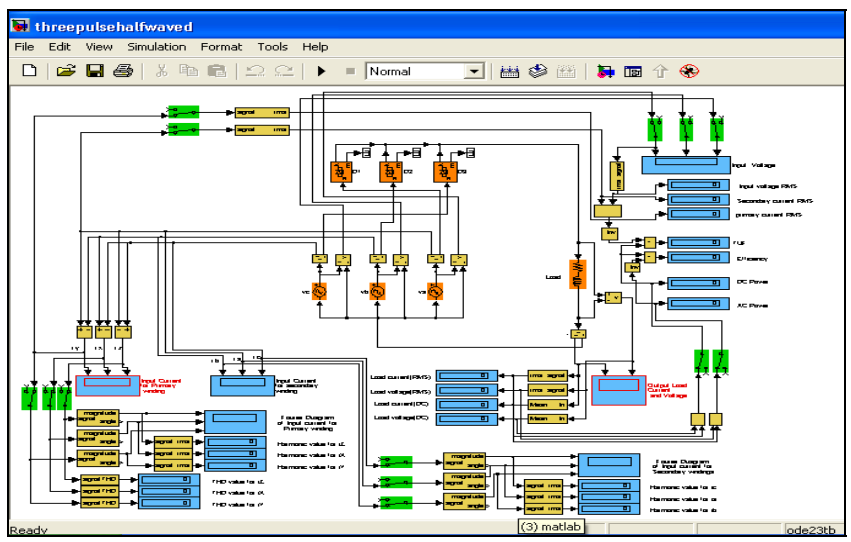

(a) 3 Pulses, Single way, not controlled

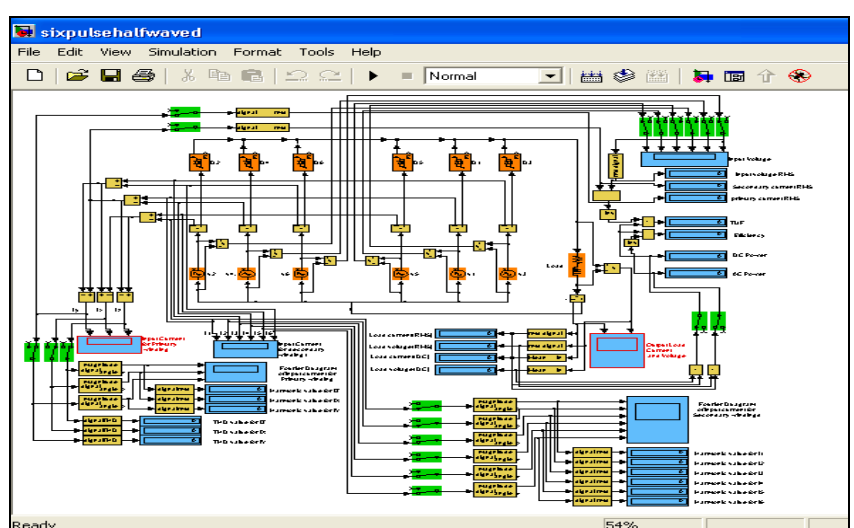

(c) Six phase - Not controlled - Without interphase

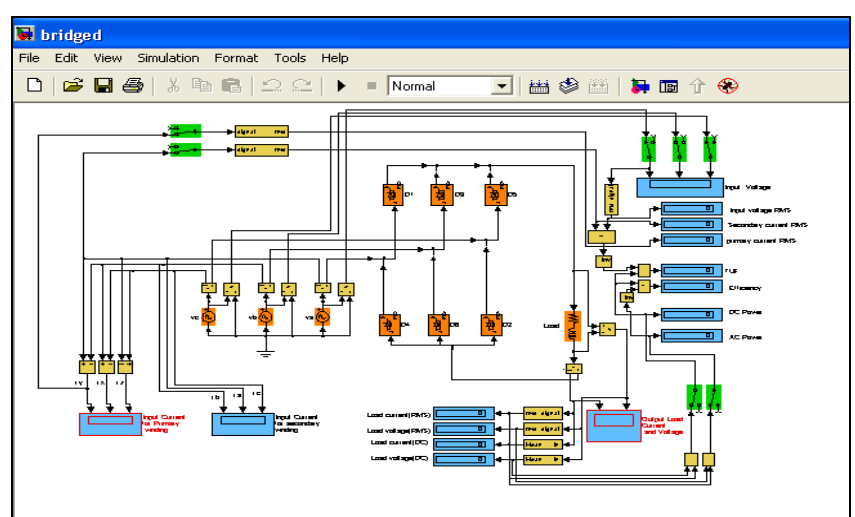

(e) 6 Pulses, Bridge connection, not controlled

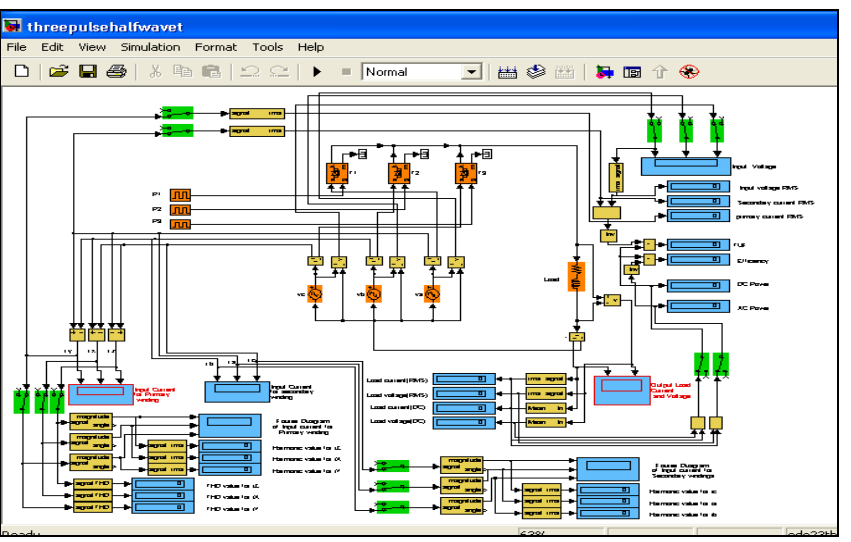

(b) 3 Pulses, Single way, Tyristor controlled

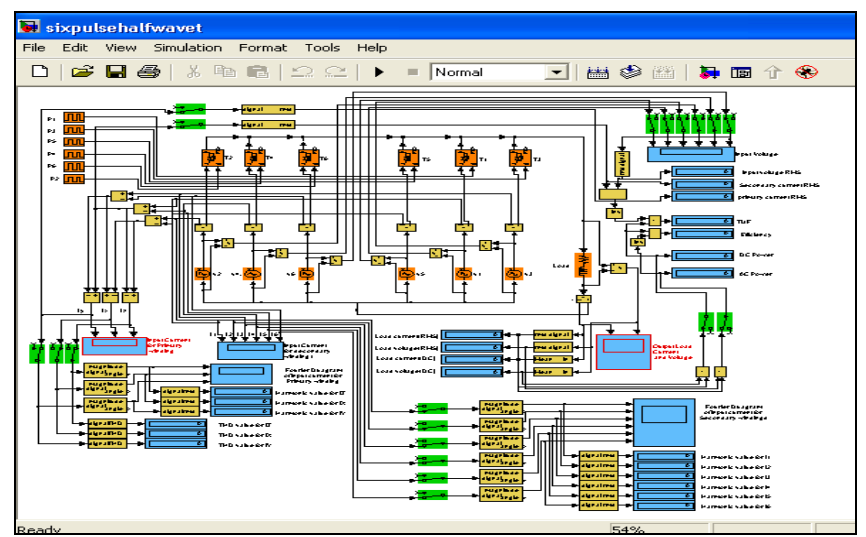

(d) Six phase - Tyristor controlled - Without interphase

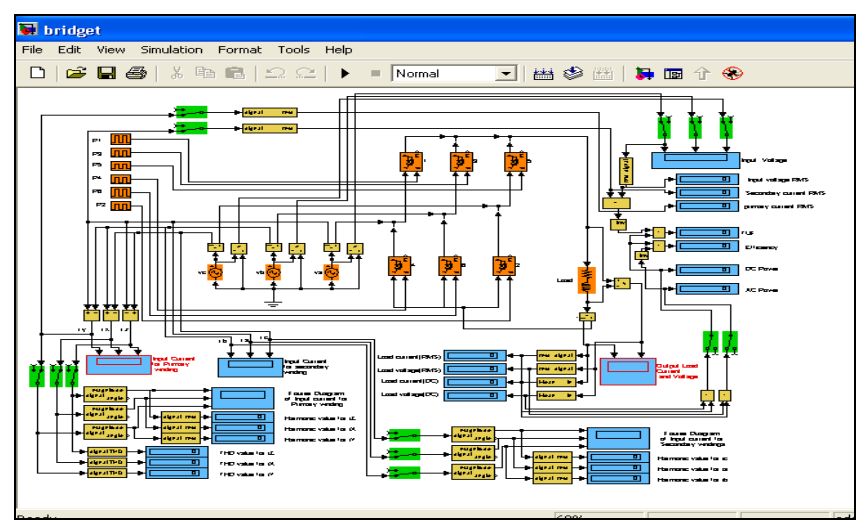

(f) 6 Pulses, Bridge connection, Tyristor controlled 


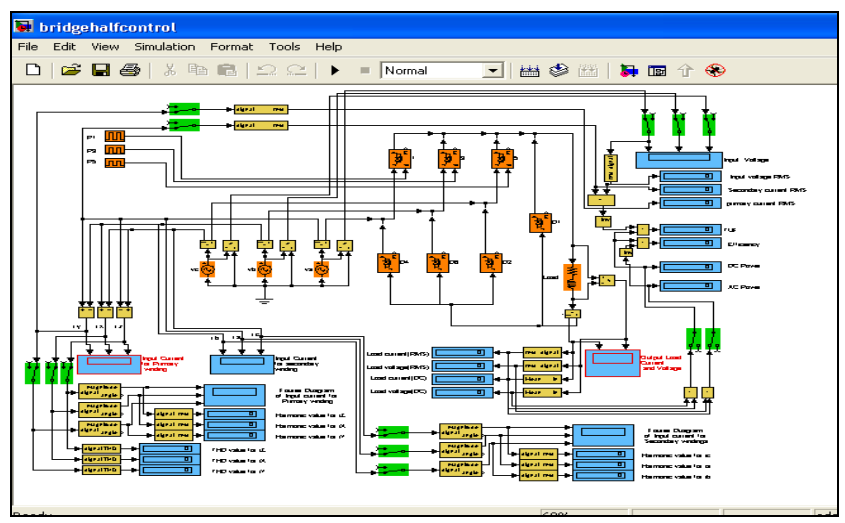

(g) 6 Pulses, Bridge connection, Half controlled

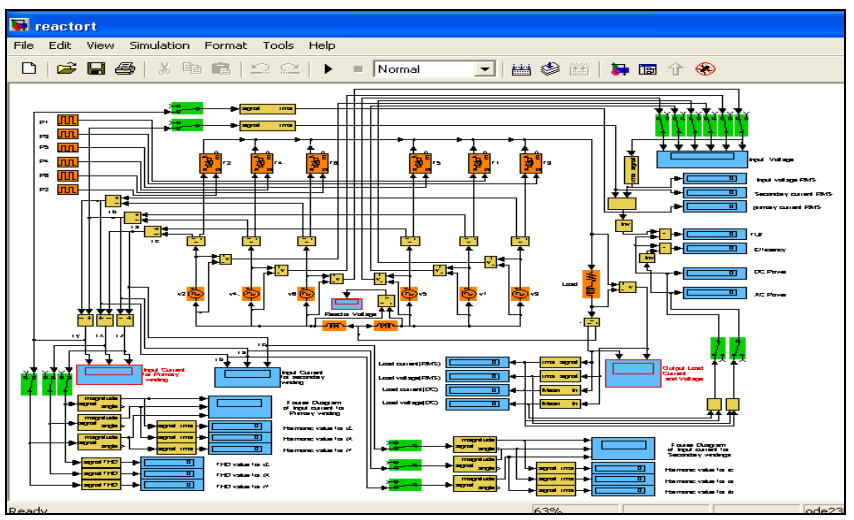

(i) Double way - Tyristor controlled -With interphase

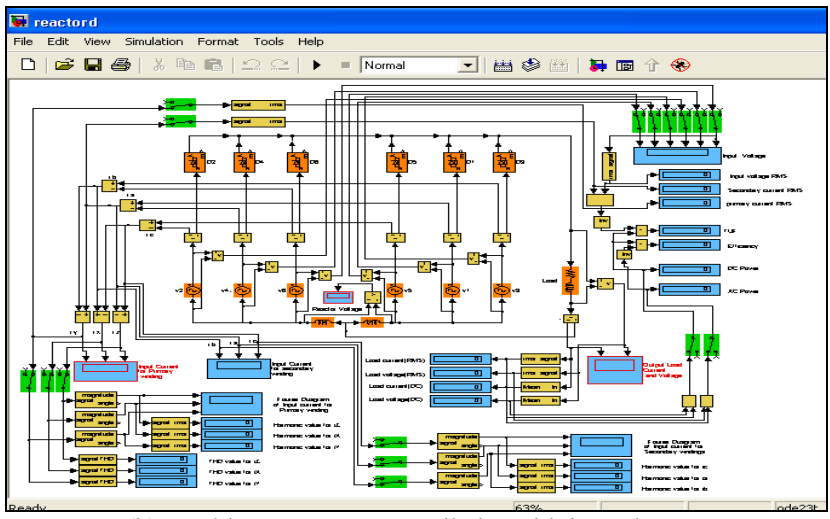

(h) Double way - Not controlled - With interphase

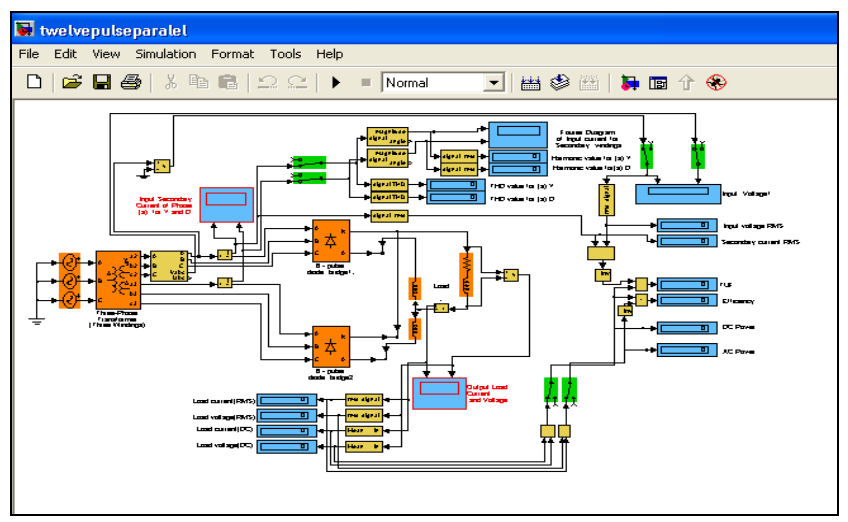

(j) 12 Pulses, Series connection of two 6-pulse

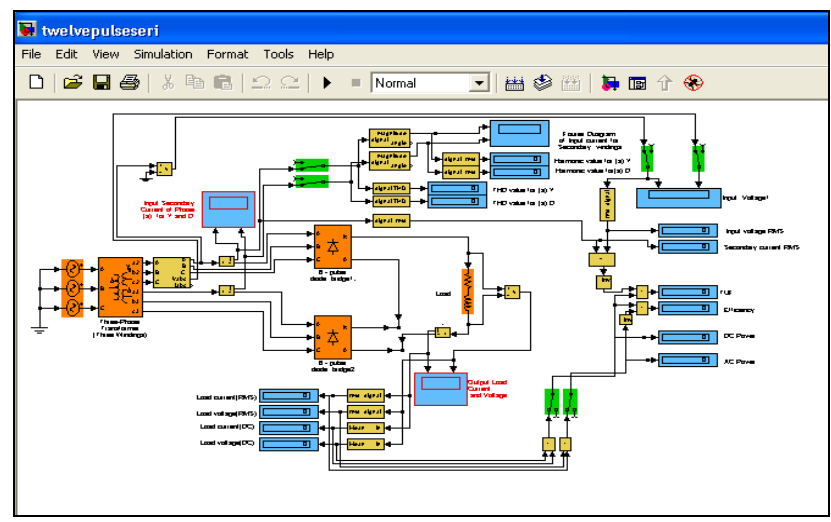

(k) 12 Pulses, Parallel connection of two 6-pulse

Fig. 1. The block diagrams of 11 rectifier circuits simulated in MATLAB/SIMULINK

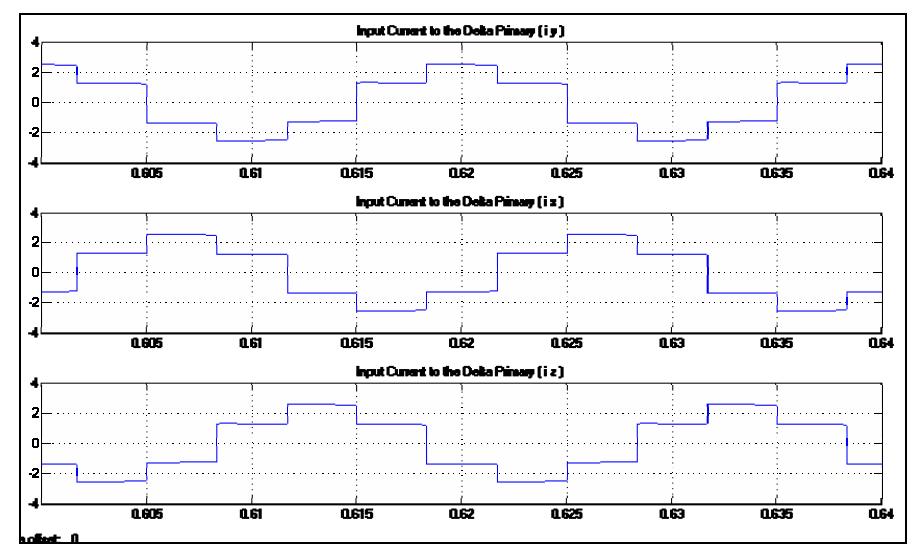

Fig. 2. An example of current waveforms of the transformer windings- extracted from simulations

Subsequently, the harmonic spectrums existing in individual windings are calculated up to 25 th harmonic order based on the extracted waveforms from the simulations and by means of Fourier series. The cut off point of 25th harmonic order is realistic [4,5]. The results of the simulations are well approved by the guidelines presented in IEEE Std. No. C57.18.10.1998 [5] for semiconductor power rectifier transformers. Table II 
summarizes the results of these calculations. These calculations. harmonic spectrums are employed as the database for next

TABLE II THEORETICAL AND TYPICAL MAGNITUDES OF HARMONIC CURRENTS PRESENT IN INDIVIDUAL WINDINGS OF THE RECTIFIER TRANSFORMER BASED ON VARIOUS RECTIFIER CIRCUITS- IN PER UNIT OF THE FUNDAMENTAL CURRENT

\begin{tabular}{|c|c|c|c|c|c|c|c|c|c|c|c|c|c|c|c|c|c|c|c|c|c|c|c|c|c|c|c|}
\hline & & & 1 & 2 & 3 & 4 & 5 & & 7 & 8 & & 10 & 11 & & & 14 & 15 & 16 & 17 & & 19 & 20 & 21 & 22 & 23 & & 25 \\
\hline & \multirow{2}{*}{ Theory } & & 10 & & & & & & & & & & & & & & 0 & & & 0 & & 0.050 & 0 & & & & \\
\hline & & Second & 10 & 0.50 & 0 & 0.2 & & 0 & & & 0 & & 0.091 & 0 & 0.070 & 0.072 & 0 & 0.063 & 0.059 & 0 & 0.053 & 0.050 & 0 & 0.046 & .043 & 0 & 0.04 \\
\hline & \multirow{2}{*}{ pical } & 1 & 10 & 49 & 0 & 0.233 & & 0 & 11 & & 0 & 062 & 0.045 & & 0.029 & 0.027 & 0 & 0.018 & 0.015 & 0 & .012 & 0.011 & 0 & 0.010 & 1.009 & 0 & 0.00 \\
\hline & & Secont & 10 & & & 0.233 & 75 & & 111 & & & 062 & 0.045 & & 0.029 & 0.027 & 0 & 0.018 & 0.015 & 0 & 0.012 & 0.011 & 0 & 0.010 & .009 & 0 & 1.00 \\
\hline & \multirow{2}{*}{ eory } & & 10 & & & 0.250 & & 0 & & & & 100 & & & & & 0 & 0.063 & 0.059 & & 0.053 & & 0 & 0.04 & 104 & & 0.0 \\
\hline & & Secon & 10 & 0.50 & 0 & 0.250 & & 0 & & & & & & & 0.070 & 0.072 & 0 & 0.063 & 0.059 & 0 & 0.053 & 050 & 0 & 0.046 & 0.0 & & 0.04 \\
\hline & \multirow{2}{*}{ pical } & & 10 & 0.49 & 0 & 0.233 & 0.175 & 0 & 0.111 & 093 & c & 0.062 & 0.045 & & 0.029 & 0.027 & 0 & 0.018 & 0.015 & 0 & 0.012 & 0.011 & 0 & 0.010 & 0.009 & 0 & 0.00 \\
\hline & & Secon & 10 & 0.49 & 0 & 0.233 & 0.175 & 0 & 0.111 & 0.093 & 0 & 0.062 & 0.045 & & 0.029 & 0.027 & 0 & 0.018 & 0.015 & 0 & 0.012 & 0.011 & 0 & 0.010 & 0.009 & 0 & 0.00 \\
\hline & \multirow{2}{*}{ teory } & & 1 & 0 & & & 0.200 & 0 & & & & & & & 0.070 & & & & 0.059 & 0 & & & 0 & & 0.043 & & 0.04 \\
\hline & & Second & 1 & c & & & 200 & 0 & & & & & 0.091 & & 0.070 & & & & 0.059 & 0 & 0 & & 0 & & 0.0 & 0 & 0.04 \\
\hline & \multirow{2}{*}{ pical } & $\mathbf{P}$ & 1 & 0 & & 0 & 0.175 & 0 & 0.111 & & & & 0.045 & 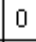 & 0.029 & & & & 0.015 & 0 & 0.01 & & 0 & & 0.009 & 0 & 0.00 \\
\hline & & Secon & 1 & 0 & & 0 & 0.175 & 0 & & & 0 & & 0.045 & & 0.029 & & 0 & & 0.015 & 0 & 0.0 & & 0 & & 0.009 & 0 & 0.00 \\
\hline & & & 1 & 0 & & & 0.200 & 0 & & & & & & & 0.070 & & & & & 0 & & & 0 & & 0.0 & & 0.04 \\
\hline & & Seco & 1 & 0 & & & 0.200 & 0 & & & 0 & & & & 0.070 & & & & & 0 & & & & & & 0 & 0.04 \\
\hline & & $\mathbf{P}$ & 1 & 0 & 0. & c & 0.175 & 0 & 0.111 & & 0 & & 0.045 & ] & 0.029 & & & & 0.015 & 0 & 0.0 & & 0 & & 0.009 & 0 & 0.00 \\
\hline & & Secon & 1 & 0 & 0 & 0 & 0.175 & 0 & 0. & & 0 & & 0.045 & 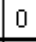 & 0.029 & & 0 & & 0.015 & 0 & 0.01 & & 0 & & 0.009 & 0 & 0.00 \\
\hline & & & 1 & 0 & & & & 0 & & & 0 & & & & 0.070 & & 0 & & & 0 & & & 0 & & & 0 & \\
\hline 5 & & Secor & 1 & 0 & 0 & & 0.200 & 0 & & & & & & & 0.070 & & & & 59 & 0 & & & & & & & 0.04 \\
\hline & & & 1 & 0 & 0 & 0 & 0.175 & 0 & & & 0 & & 0.045 & 0 & 0.029 & ( & 0 & & 0.015 & 0 & 0.0 & & 0 & & 0.009 & 0 & 0.00 \\
\hline & & SecoI & 1 & 0 & 0 & & 0.175 & 0 & 0 & & 0 & & 0.045 & & 0.029 & & & & 0.015 & 0 & 0.0 & & 0 & & 0.009 & 0 & 0.00 \\
\hline & & & 1 & 0 & 0 & & & 0 & & & 0 & & & & & & & & & 0 & & & & & & & 0.0 \\
\hline 6 & & Secor & 1 & c & . & & 0.200 & & & & & & 0091 & & 0.07 & & & & 0.0 & 0 & & & & & 1.0 & & 0.04 \\
\hline & & & 1 & 0 & 0 & 0 & 0.175 & 0 & & & 0 & & 0.045 & 0 & 0.029 & & 0 & & 0.015 & 0 & 0.0 & & 0 & & 0.009 & 0 & 0.00 \\
\hline & & Seco & 1 & 0 & 0 & & 175 & 0 & 0.111 & & 0 & & 0.045 & J & 0.029 & ( & 0 & & 0.015 & 0 & 0.0 & & 0 & & 0.009 & 0 & 0.00 \\
\hline & & & 1 & & & & & 0 & & & & & & & & & & & & 0 & & & & & & & \\
\hline & & & 1 & 0 & م. & 0 & 0.200 & 0 & & & 0 & & 0.091 & & 0.070 & & 0 & & 0.0 & 0 & & & 0 & & & 0 & 0.04 \\
\hline & & & 1 & 0 & 0 & 0 & 0.175 & 0 & 0.1 & & 0 & & 0.045 & 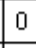 & 0.02 & & & & 0.015 & 0 & & & 0 & & 0.0 & 0 & 0.00 \\
\hline & & & 1 & 0 & 0 & & & 0 & & & 0 & & & 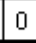 & 0.029 & & 0 & & & 0 & & & 0 & & .0 & 0 & 0.00 \\
\hline & & & & & & & & 0 & & & 0 & & & & & & & & & 0 & & & & & & & \\
\hline & Theory & Secondary & 10 & 0.50 & 0 & 0.250 & 0.200 & 0 & 0.143 & 0.125 & 0 & 0.100 & 0.091 & 0 & 0.070 & 0.072 & 0 & 0.063 & 0.059 & 0 & 0.053 & 0.050 & 0 & 0.04 & 0.0 & 0 & 0.04 \\
\hline & & \begin{tabular}{|l|} 
Tertiary \\
\end{tabular} & 10 & 0.50 & 0 & 0.250 & 0.200 & 0 & 0.143 & 0.125 & 0 & 0.100 & 0.091 & 0 & 0.070 & 0.072 & 0 & 0.063 & 0.059 & 0 & 0.053 & 0.050 & 0 & 0.046 & 0.043 & 0 & 0.04 \\
\hline & & & 1 & 0 & 0 & 0 & 0.175 & 0 & 0.11 & & 0 & & 0.04 & $10^{\circ}$ & 0.029 & & 0 & & 0.015 & 0 & 0.0 & & 0 & & 0.0 & & 0.00 \\
\hline & & & 10 & & 0 & & & 0 & & & 0 & & & & & & 0 & & & 0 & & & 0 & & & & \\
\hline & & & 10 & 0.49 & 0 & 0.233 & 0.175 & 0 & 0.111 & 0.093 & 0 & 0.062 & 0.045 & 0 & 0.029 & 0.027 & 0 & 0.018 & 0.015 & 0 & 0.012 & 0.011 & 0 & 0.0 & 0.0 & 0 & 0.00 \\
\hline & & & 1 & 0 & 0 & 0 & 0.200 & 0 & 0.143 & & 0 & & 0.091 & 0 & 0.070 & & 0 & & 0.059 & 0 & 0.0 & & 0 & & 0.043 & 0 & 0.04 \\
\hline & & Second & 10 & 0.50 & 0 & 0.250 & 0.200 & 0 & 0.143 & 125 & 0 & 0.100 & 0.091 & 0 & 0.070 & 0.072 & 0 & 0.063 & 0.059 & 0 & 0.053 & 0.05 & 0 & 0.0 & 0.0 & 1 & 0.04 \\
\hline & & & 10 & 0.50 & 0 & 0.250 & 0.200 & 0 & & 125 & 0 & 0.100 & & & 0.070 & 0.072 & 0 & & & 0 & & 0.0 & 0 & & & & 0.0 \\
\hline & & & 1 & 0 & 0 & 0 & 0.175 & 0 & 0.111 & 0 & 0 & & 0.045 & 0 & 0.029 & 0 & 0 & & 0.015 & 0 & 0.0 & & 0 & & 0.009 & 0 & 0.00 \\
\hline & & Second & 10 & 0.49 & 0 & 0.233 & 0.175 & 0 & 0.111 & 0.093 & 0 & 0.062 & 0.045 & 0 & 0.029 & 0.027 & 0 & 0.0 & 0.015 & 0 & 0.012 & 0.01 & 0 & 0.0 & 0.0 & 0 & 0.00 \\
\hline & & & 10 & 0.49 & 0 & 0.23 & 0.175 & 0 & 0.11 & & 0 & & & 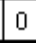 & 0.029 & 0.027 & 0 & & 0.015 & 0 & 0.012 & 0.01 & 0 & & 0.009 & 0 & 0.00 \\
\hline & & & 1 & & & & & & & & & & & & & & & & & & & & 0 & & & & 0.04 \\
\hline & & Secondary & 1 & 0 & & 0 & 0.200 & 0 & 0.143 & & 0 & & 0.091 & 0 & 0.070 & & 0 & & 0.059 & 0 & 0.0 & & 0 & & 0.043 & 0 & 0.04 \\
\hline & & & 1 & 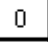 & & & 0.200 & 0 & 0.1 & & 0 & & 0.091 & 0 & 0.07 & & 0 & & 0.059 & 0 & 0.0 & & 0 & & 0.043 & 0 & 0.04 \\
\hline & & & 1 & 0 & & & c & 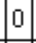 & & & & & & 0 & 0.0 & & & & & 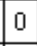 & & & 0 & & D.0009 & 0 & 0.00 \\
\hline & Typical & Second & 1 & 0 & & & & 0 & & & & & & 0 & & & & & & 0 & & & 0 & & & & 0.00 \\
\hline & & & 1 & 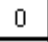 & & & & 0 & & & 0 & & 0.0 & 0 & 0.02 & & & & 0.015 & 0 & & & 0 & & & 0 & 0.00 \\
\hline & & & 1 & 0 & 1 & & 0 & D & & & $\omega^{0}$ & & 0.091 & 0 & 0.07 & & & & & 0 & & & 0 & & 0.043 & 0 & 0.04 \\
\hline & Theory & Secondary & 1 & 0 & 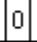 & 0 & 0.200 & 0 & 0.14 & & 0 & & 0.091 & 0 & 0.070 & & 0 & & 0.059 & 0 & 0.053 & & 0 & & 0.043 & 0 & 0.04 \\
\hline & & & 1 & 0 & & 0 & 0.200 & & 0.143 & & & & & I & 0.07 & & & & 0.059 & 0 & 0.0 & & & & 0.043 & 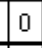 & 0.04 \\
\hline & & & 1 & ( & & c & 0 & 0 & 0 & & 0 & & 0.0 & 0 & 0.0 & c & & & & 0 & & & 0 & & 0.009 & 0 & 0.00 \\
\hline & & Secor & 1 & 0 & 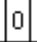 & 0 & 0.175 & 0 & 0.1 & & [0 & & 0.045 & 0 & 0.02 & C & 0 & & 0.015 & 0 & 0.0 & 0 & 0 & & 0.009 & 0 & 0.00 \\
\hline & & ertiary & $L^{2}$ & 0 & & 0 & 0.175 & & 0.111 & & & & 0.045 & 0 & 0.029 & 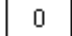 & & & 0.015 & 0 & 0.010 & 0 & 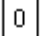 & & 0.009 & & 0.00 \\
\hline
\end{tabular}


Theoretical spectrums provide very conservative values for the magnitude of harmonic currents since they are related to no-load conditions of rectifier circuits [4,5]. In practice and under load conditions, the magnitude of harmonic currents will decrease a lot [4]. Thus, typical values [4] are usually applied for harmonic currents. The typical values are based on load impedance and firing delay of thyristors in controlled rectifiers. In several case studies presented in IEEE Standard [5] for harmonic loss calculations, typical spectrums are used. These values are also presented in Table II. In the developed approach, it is possible to select either theoretical or typical spectrums for doing the calculations in order to get the best condition.

\section{A REVIEW OF HARMONIC CURRENTS EFFECTS ON THE TRANSFORMER FIGURES AND TABLES}

\section{A. No-load losses}

Harmonic load currents do not influence the no-load losses and hence, they can be considered as constant when the transformer supplies non-sinusoidal load currents $[5,8]$.

\section{B. Ohmic losses}

If the RMS value of the load current is increased as a result of the harmonic currents, the Ohmic losses under this condition will be described by:

$$
P_{\text {Ohmic Loss }}^{\prime}=P_{\text {Ohmic Loss }} *\left(I_{R M S h(P U)}\right)^{2}
$$

where,

$P^{\prime}$ Ohmic Loss: Total Ohmic losses under harmonic condition.

$P_{\text {Ohmic Loss: }}$ Total Ohmic losses under sinusoidal condition.

$I_{R M S h}(P U)$ : The RMS value of harmonic load currents in terms of Per Unit

However, the Ohmic losses will be unaffected from normal sinusoidal operation if the RMS value of load current is maintained at the presence of harmonic currents [4].

\section{Windings Eddy Current losses}

Windings Eddy current losses are affected by the harmonic components more than other losses [2, 8]. The eddy current losses generated by harmonic load currents, will influence the most limiting feature in thermal design of a transformer which is the temperature rise of the transformer hot spot $[3,4]$. The winding eddy current harmonic loss factor in terms of perunit, $\mathrm{F}_{\mathrm{HL}-\mathrm{WE}}$, is defined as [5]:

$$
F_{H L-W E}=\frac{\sum_{1}^{n} I_{h}(p u)^{2} h^{2}}{\sum_{1}^{n} I_{h}(p u)^{2}}
$$

Where,

$F_{H L-W E}$ : Winding eddy current harmonic loss factor in terms of perunit,

$I_{h(P U)}$ : Harmonic component of current of the order pointed out by the subscript h;

$h$ : Order of harmonic.

Total windings Eddy Current losses under harmonic load current conditions $\left(P_{H L-W E}^{\prime}\right)$, is described as [5]:

$$
P_{E C}^{\prime}=P_{E C-p}\left(F_{H L-W E}\right)+P_{E C-s}\left(F_{H L-W E}\right)+P_{E C-t}\left(F_{H L-W E}\right)
$$

where,

$P_{E C-P:}$ the eddy current loss of primary windings;

$P_{E C-S}$ : the eddy current loss of secondary windings;

$P_{E C-T}$ : the eddy current loss of tertiary windings, if any.

\section{Other Stray losses}

Other stray losses, which take place in core clamps, structures, and tank or enclosure walls [4], will increase when a transformer is subjected to a load current having harmonic components compared to the cases that it supplies a sinusoidal load current.

Other stray loss harmonic factor, $\mathrm{F}_{\mathrm{HL}-\mathrm{OSL}}$, in terms of the Per Unit is defined as [5]:

$$
F_{H L-O S L}=\frac{\sum_{1}^{n} I_{h}(p u)^{2} h^{0.8}}{\sum_{1}^{n} I_{h}(p u)^{2}}
$$

where,

$F_{H L-O S L}$ : Harmonic loss factor of other stray losses,

$I_{h}(P U)$ : Harmonic component of current of the order indicated by the subscript $h$,

$h$ : Order of harmonic.

Consequently, other stray losses under harmonic load current conditions $\left(P_{\text {OSL }}^{\prime}\right)$, is presented by:

$$
P_{O S L}^{\prime}=P_{O S L} \times\left(F_{H L-O S L}\right)
$$

where, $P_{O S L}$ is the other stray loss under sinusoidal condition.

\section{E. Temperature rise}

All of the above discussed effects will cause an increase in the transformer losses compared to the cases it supplies sinusoidal load currents. These increased losses will increase the temperature rise of the transformer from its sinusoidal value. The main effect in designing a rectifier transformer is that it must be capable of cooling the total transformer loss [2, 4]. Besides, the windings must manage to handle the additional losses. This necessitates that the windings hot spot is de-rated to stand these higher losses. Hence, the following equations may be employed to calculate the de-rated oil and windings sinusoidal temperature rise [4]: De-rated sinusoidal oil rise $=(($ total sinusoidal losses)
$($ total harmonic losses $))^{0.8} \times K$

De-rated sinusoidal winding rise $=(($ load sinusoidal losses $)$ ) (load harmonic losses)) ${ }^{0.8} \times K$

where,

$K$ is the temperature rise for normal sinusoidal operation.

\section{F. Current rating}

The RMS value of load current is higher when the transformer supplies harmonic load currents. At the presence of the harmonics, the RMS value of load current is described as [5]: 


$$
I_{R M S h(P U)}=\sqrt{\sum_{h=1}^{n} I_{h(P U)}^{2}}
$$

where,

$I_{R M S h(P U)}$ : The RMS value of harmonic load currents in terms of per unit,

$I_{h}(P U)$ : Harmonic component of current of the order indicated by the subscript $h$.

Equation (8) will give an approximate value for the RMS current as only up to $25^{\text {th }}$ harmonic order are included. When using the typical harmonic spectrum, a fully exact calculation would increase the RMS current value about $\% 2.33$ more [4]. However, when using the theoretical harmonic spectrum, as it gives a conservative value for the magnitude of harmonic currents, it is not required to add the $\% 2.33$ factor [5].

\section{G: De-rated KVA}

De-rated KVA of the transformer is another important subject in studying the harmonics effects. This is particularly true when normal transformers are subjected to DC load currents. Rated KVA of the transformer when supplying harmonic load currents is defined as [4]:

$$
\operatorname{Rated}(K V A)=\left(V_{L}\right)\left(I_{R M S s h}\right) \times \sqrt{3} / 1000
$$

where,

$V_{L}$ : Line voltage,

$I_{R M S h}$ : The RMS value of harmonic load currents.

The rated KVA calculated from (9) may exceed the nominal KVA of the transformer. Hence, its nominal KVA for sinusoidal operation should be lowered enough — called De-rating - so that the transformer can cool the harmonic losses without over heating [8]. De-rated KVA can be given by:

$$
\operatorname{Derated}(K V A)=S_{n} \frac{I_{L}}{\mathrm{I}_{r m s h}}
$$

where,

$S_{n}$ : nominal KVA in sinusoidal operation,

$I_{L}$ : The RMS value of load current in sinusoidal operation, $I_{R M S h}$ : The RMS value of harmonic load currents.

\section{PROPOSED APPROACH}

The developed approach for accurate designing of transformers which supply DC load currents is carried out by means of a coded program created in MATLAB and based on the simulations presented in Section II and harmonic spectrums extracted from them. The performing algorithm of the proposed method is depicted in Fig. (3).

In the following, a description of each step is given:

1) Selection of the rectifier: This is done using the guide in (1) above and entering its code. These codes are also summarized in Table (1).

2) Choosing the harmonic spectrum: According to the definitions presented in (II), one of the theoretical/typical harmonic spectrums is selected so that the calculations are done based on the chosen spectrum.

3) Entering the load current: Either DC or RMS value of the load current may be entered.
4) Entering the data of the transformer in sinusoidal operation: This data is often available in documents of transformer manufacturers, or can simply be acquired through some routine tests at the workshop. The data include rated KVA of the transformer, the connection type of the primary, secondary, and if any, tertiary windings, rated voltage of individual windings, total Ohmic loss of entire windings, total core loss, eddy current losses of individual windings, total other stray losses, and temperature rise.

5) Calculations: In this stage, the appropriate calculations are done based on the equations (1) to (10) introduced in (III) and other usual equations utilized in transformers.

6) Presenting the results: Finally, the required parameters in designing a transformer, when supplying harmonic load currents, are presented based on the selected rectifier and harmonic spectrum. These parameters include de-rated KVA, Line and Phase currents of individual windings, eddy current losses of individual windings, total other stray losses, total Ohmic losses, total load losses, total losses of the transformer, and de-rated temperature rise for windings and oil.

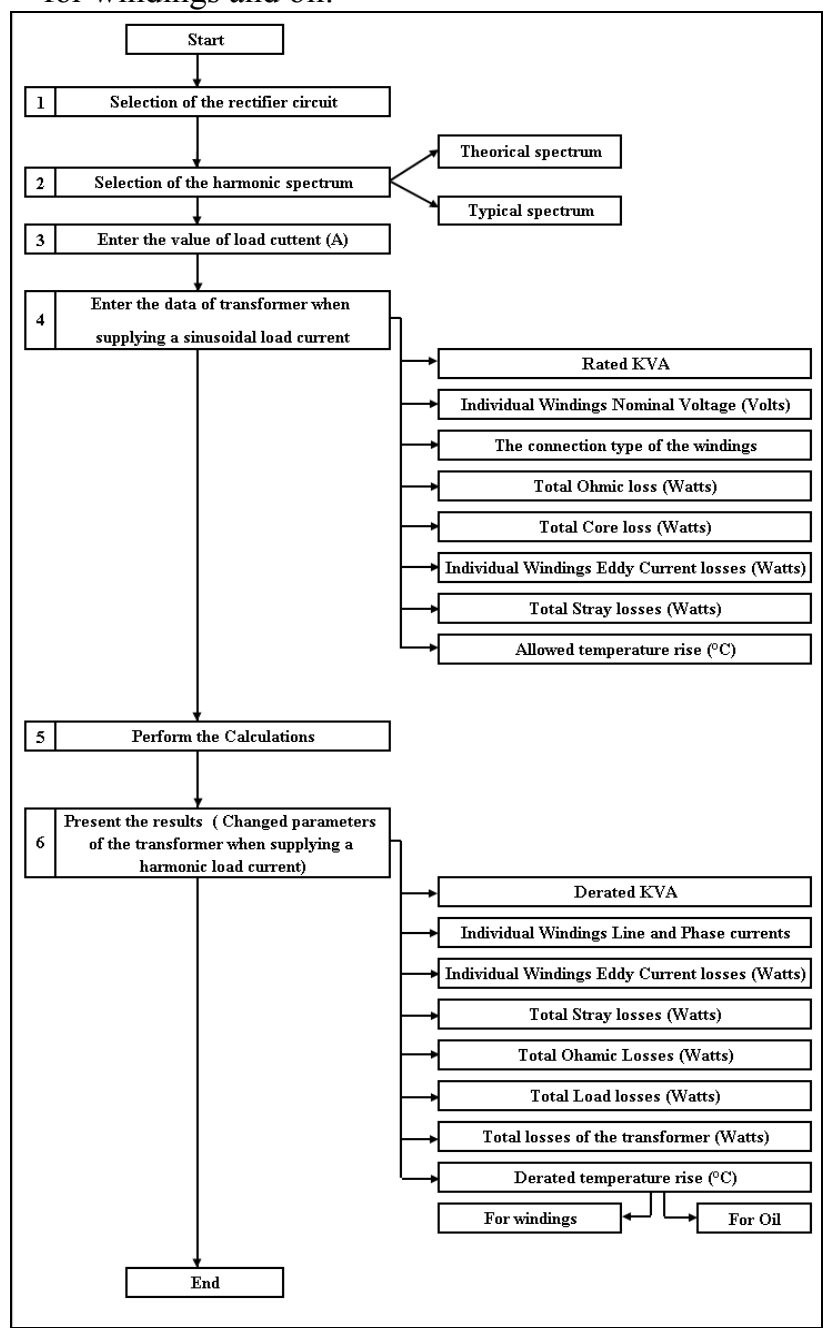

Fig. 3. The performing flowchart of the developed software

\section{CASE STUDY}

In order to evaluate the proposed approach, the example No.4 of IEEE Standard No.C57.18.10.1998 [5] for semiconductor power rectifier transformers is analyzed by the developed approach as a case study. The input data are 
summarized in Table (3). The transformer has two paralleled primary windings. The results are presented in Table (4). Comparing the results acquired here with those given in the IEEE Standard [5] well approves the capabilities of the suggested approach.

$$
\text { TABLE (3) }
$$

THE INPUT DATA OF THE SOFTWARE FOR THE CASE STUDY OF THE EXAMPLE NO.4 OF IEEE STANDARD NO.C57.18.10.1998

\begin{tabular}{|c|c|c|}
\hline \multicolumn{2}{|c|}{ Input Parameter ( Normal Condition ) } & Value \\
\hline \multicolumn{2}{|c|}{ Rectifier Code } & 10 \\
\hline \multicolumn{2}{|c|}{ Type of Harmonic Spectrum } & Typical \\
\hline \multicolumn{2}{|c|}{ Rated (KVA) } & 15000 \\
\hline \multicolumn{2}{|c|}{ Load Current (RMS) } & 984.12 \\
\hline Connection of Windings & \multicolumn{2}{|c|}{$\mathrm{D} / \mathrm{d} \mathrm{y}$} \\
\hline Voltage (V) & \multicolumn{2}{|c|}{$12000 / 4400 / 4400$} \\
\hline \multirow{3}{*}{$\begin{array}{l}\text { Windings Eddy current } \\
\text { Losses(Watts) }\end{array}$} & Primary (each) & 240 \\
\hline & Secondary & 850 \\
\hline & Tertiary & 1267 \\
\hline \multicolumn{2}{|c|}{ Other Stray Losses(Watts) } & 5107 \\
\hline \multicolumn{2}{|c|}{ Ohmic Losses(Watts) } & 55814 \\
\hline \multicolumn{2}{|c|}{ Core Loss(Watts) } & 21700 \\
\hline \multicolumn{2}{|c|}{ Temperature $\operatorname{Rise}\left({ }^{\circ} \mathrm{C}\right)$} & 75 \\
\hline
\end{tabular}

TABLE (4)

THE OUTPUT DATA OF THE SOFTWARE FOR THE CASE STUDY OF THE EXAMPLE NO.4 OF IEEE STANDARD NO.C57.18.10.1998

\begin{tabular}{|c|c|c|c|}
\hline \multicolumn{3}{|c|}{ Output Parameter ( Harmonic Condition) } & Value \\
\hline \multicolumn{3}{|c|}{ Rated (KVA) } & 15376 \\
\hline \multicolumn{3}{|c|}{ De-rated (KVA) } & 14624 \\
\hline \multirow{6}{*}{$\begin{array}{l}\text { Load Currents } \\
\quad \text { (RMS) }\end{array}$} & \multirow{2}{*}{ Primary (each) } & Line & 367.87 \\
\hline & & Phase & 213.88 \\
\hline & \multirow{2}{*}{ Secondary } & Line & 1010 \\
\hline & & Phase & 583.81 \\
\hline & \multirow{2}{*}{ Tertiary } & Line & 1010 \\
\hline & & Phase & 1010 \\
\hline \multirow{3}{*}{\multicolumn{2}{|c|}{$\begin{array}{l}\text { Windings Eddy current Losses } \\
\text { (Watts) }\end{array}$}} & Primary & 694.5 \\
\hline & & Secondary & 2460 \\
\hline & & Tertiary & 3663 \\
\hline \multicolumn{3}{|c|}{ Other Stray Losses (Watts) } & 6087 \\
\hline \multicolumn{3}{|c|}{ Total Ohmic Losses (Watts) } & 58369 \\
\hline \multicolumn{3}{|c|}{ Total Load Losses (Watts) } & 71968 \\
\hline \multicolumn{3}{|c|}{ Total Losses of the transformer (Watts) } & 93668 \\
\hline \multirow{2}{*}{\multicolumn{2}{|c|}{ Temperature Rise $\left({ }^{\circ} \mathrm{C}\right)$}} & Oil & 69.53 \\
\hline & & Winding & 67.86 \\
\hline
\end{tabular}

\section{CONCLUSION}

Transformers which supply DC load currents, and are called rectifier transformers, have different characteristics compared to typical transformers that supply sinusoidal load currents. Harmonic currents in these transformers are very important in designing the transformer parameters and they will cause over heating and hence serious problems if they are not evaluated properly. In this paper, an approach is proposed for exact designing of transformers supplying DC load currents. The presented approach simulates the transformer and the required rectifier circuit at the same time and extracts the harmonic currents spectrums. Next, the transformer parameters are designed based on the extracted harmonic spectrums and their effects on the transformer. A design engineer may use the results of this approach in designing and rating of rectifier transformers optimally regarding technical features and cost attitudes. Besides, the presented approach may be employed for de-rating the typical transformers which are subjected to harmonic currents.

\section{REFERENCES}

[1] Kennedy, P., "Design and Application of Semiconductor Rectifier Transformers", IEEE Transactions on industry Applications, Vol. 38 , No. 4, July/August 2002.

[2] [2] M.Salih TACT, M.Hadi SARUL, Gulderen YILDIRMAZ, " The Effects of Harmonic Currents upon Transformer Active Losses in Case of (Non)Sinusoidal Sources and (Non)Linear Loads", IEEE Paper No. 0-7803-5812-0/ 00, 2000.

[3] Johan Driesen et al., " Practical Method to Determine Additional Load Losses due to Harmonic Currents in Transformers with Wire an Foil Windings", IEEE Paper No. 0-7803-5935-6/00, 2000.

[4] Sheldon P.Kennedy \& C.L.Levy, "Application, Design and Rating of Transformers Containing Harmonic Currents", PPIC- 90 - 35, IEEE, 1990.

[5] IEEE Standard No.C57.18.10.1998, for Semiconductor Power rectifier transformers, 1998.

[6] Cyril Lander," Power Electronics", April, 2005.

[7] Muhammad H. Rashid, " Power Electronics; Circuits, Devices and Applications", 3rd Edition, August, 2003.

[8] Linden W.Pierce, "'Transformer Design and Application Considerations for Non-sinusoidal load Currents", IEEE Paper No.0093/96, 1996. 